\title{
A revista 0 Cruzeiro e o desenvolvimentismo: natureza e imagens do Brasil moderno no governo JK
}

\author{
Jorge Luiz Romanello \\ Doutor em História pela Universidade Estadual Paulista Júlio de Mesquita Filho (UNESP-Assis). \\ Professor do Departamento de História da Universidade Estadual de Londrina. \\ ediromanello@yahoo.com.br
}

\section{Resumo}

O objetivo neste texto é discutir a forma como a natureza integrou o elenco de temas da revista 0 Cruzeiro no período de 1954 a 1961. A definição deste corte temporal específico deu-se em função de diversos fatores. Naquele contexto, a economia e a cultura passam por modificações rápidas e importantes, provocando impactos variados em várias esferas da sociedade brasileira, um estudo mais aprofundado da década permite perceber profundas alterações no debate em torno do desenvolvimento econômico e da própria escolha do modelo de capitalismo a ser adotado no Brasil, ao mesmo tempo em que ocorriam importantes mudanças nos sistemas de comunicação de massas, com a inauguração da televisão e 0 amadurecimento do fotojornalismo nas revistas ilustradas, entre outras.

PalaVRAs-chaVe: natureza; desenvolvimento econômico; sistemas de comunicação de massas.

\section{ABstract}

The aim of this text is to discuss the way nature was present in the cast of themes of 0 Cruzeiro magazine from 1954 to 1961. The definition of this temporal clipping is due to many factors. In that context, economy and culture were going through rapidly and important modifications, causing diverse impacts in some spheres of Brazil 's society. M aking a profound study of the decade, allows us to realize the deep alterations in the debate about the economic development and the choice of a model of capitalism to be followed in Brazil, at the same time, there were happing important transformations in mass communication system, with the inauguration of television and the maturation of photojournalism in illustrated magazines, among others. KEY WORDS: nature; economic development; mass communication system. 


\section{A revista 0 Cruzeiro e o desenvolvimentismo: natureza e imagens do Brasil moderno no governo JK}

Os resultados aqui apresentados, são parte de uma pesquisa de doutorado inédita intitulada "A Natureza no Discurso Fotográfico da Revista 0 Cruzeiro: paisagens e imaginários no Brasil desenvolvimentista 1954-1961" iniciada no ano de 2001 e concluída no ano de 2006 no programa de pósgraduação em história da UNESP de Assis.

O meu objetivo com a escolha deste recorte é discutir uma leitura possível de algumas séries de representações da natureza, que integraram o elenco de temas da revista 0 Cruzeiro no período de 1954 a 1961.

Possuindo grande importância no cenário cultural e político do país, o Cruzeiro atingia um público de mais de três milhões de leitores em meados da década de 1950. Pessoas de diversas faixas etárias e sociais, de ambos os sexos, que consumiam semanalmente idéias, propagandas e uma série de outros produtos, veiculados principalmente por meio de grandes quantidades de fotografias majoritariamente em preto e branco, e algumas coloridas que articuladas nos padrões edito riais do fotojornalismo, definiam o perfil da publicação.

No período estudado, - seguindo uma longa tradição já característica da revista ao longo de sua história - a natureza foi objeto explícito de algumas reportagens de 0 Cruzeiro, no entanto, era de forma indireta, na abordagem de uma infinidade de assuntos, que o tema mais aparecia nas páginas da revista.
Algumas vezes a tônica das coberturas ressaltava aspectos exóticos e peculiaridades da paisagem e da geografia e mesmo da cultura e das tradições dos povos de várias regiões do planeta, como no caso das reportagens internacionais sobre o Pólo Sul e a Patagônia. Já em outras caracterizavam a produção sob variadas abordagens, como no caso das reportagens sobre a construção das usinas hidrelétricas e das estradas na selva onde as imagens promoviam o espetacular. Como convite a modernização, publicava-se artigos sobre os desenvolvimentos da agricultura, ou denuncia de práticas arcaicas no cultivo da terra e na criação de animais e até no subaproveitamento de diversas riquezas naturais.

Integrando o cotidiano da publicação também de outras formas, é possível encontrar a natureza enquanto elemento definidor das paisagens urbanas, como seu complemento, ou mesmo como contraponto para o asfalto ou o concreto que caracterizam estes espaços. Também era possível encontrar reportagens sobre os namorados que passeiam nos jardins, ou ainda, quando o tema - bastante recorrente - eram as praias, que na maioria das vezes eram representadas como uma espécie de "faixa limite" entre os domínios da natureza, representados pelo mar e os domínios do homem representados pelas cidades.

Dentro dessa diversidade, neste trabalho foram elaboradas várias tipologias, sendo que Natureza e fontes de riquezas, Natureza e 


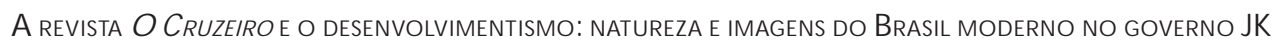

desenvolvimento econômico, e Natureza e Aspectos do M undo Rural, serão discutidas neste texto.

No contexto mais amplo da publicação percebe-se, portanto, que a natureza foi representada nas suas mais diversas perspectivas, algumas vezes ocupando o centro de foco, como o tema principal das matérias e reportagens, mas também como pano de fundo ou mesmo uma moldura para a cobertura de diversos outros assuntos. Tais procedimentos forneceram suportes para que a revista construísse uma série de discursos sobre a cidade e o campo, o progresso e 0 atraso, ou a própria paisagem, instituindo ou reafirmando valores.

A partir do estudo aprofundado de algumas reportagens que caracterizam estas tipologias, procura-se entender, a concepção de natureza que 0 Cruzeiro ajudou a forjar, os valores que projetavam e os mecanismos utilizados para atingir estas finalidades.

A definição deste corte temporal específico deu-se em função de que no período de 1956 a 1961, confluíram diversos fatores econômicos políticos e culturais de grande importância para a sociedade brasileira. E entre eles talvez os mais importantes tenham sido: o processo de industrialização acelerada e a o planejamento e a execução de grande número de obras públicas.

Recuar a pesquisa ao ano de 1954, período, portanto, anterior ao início do governo JK, e avançá-la por um período posterior ao seu término, em março de 1961, foi um procedimento metodológico fundamental, na medida em que permitiu uma comparação de padrões editoriais, temáticos e entre o tipo de discursos imagéticos produzidos. Acompanhar detalhadamente todo o desenvolvimento do governo de Juscelino, período central na elaboração e emissão dos princípios do nacional desenvolvimentismo, por sua vez permitiu avaliar e quantificar as séries estudadas.

Vale ainda lembrar a própria importância, ressaltada por uma série de especialistas, que da década de 1950 teve na história de 0 Cruzeiro. U ma fase marcada pela glória, em que associavam-se as grandes tiragens a um fotojornalismo sintonizado com as vanguardas da época.

A média geral de fotos publicadas por edição, incluindo as utilizadas em propagandas, era de aproximadamente 200 , sendo que menos de $10 \%$ delas coloridas.

Foram selecionados ao todo cerca de 390 artigos e reportagens, especificamente relacionados ao tema, de um total aproximado de 600 inicialmente arrolados.

$\mathrm{Na}$ execução desta pesquisa foram consultados todos os 417 exemplares da revista circulados no período de 1954 a 1961, aproximadamente 52 edições por ano (cerca de $70 \%$ deles em originais e $30 \%$ em microfilmes), com uma tiragem semanal média de 550.000 exemplares.

No conjunto selecionado, a distribuição dos assuntos deu-se da seguinte maneira: Natureza e paisagens 50 artigos, Natureza e desenvolvimento econômico 74 artigos, A Natureza entre o urbano e o rural 262 artigos.

As análises se desenvolveram de modo a procurar primeiro entender 0 sentido que a revista desejou fornecer aos conjuntos de fotografias que compunham cada reportagem. Neles foi analisada a interação do conjunto formado pelas imagens, título, subtítulos, legendas e boxes. Em um segundo momento, a atenção voltou-se para as possíveis articulações que as representações criavam entre os diversos temas e os imaginários do desenvolvimento econômico, do progresso e outros.

Sempre que possível, privilegiou-se 0 
estudo das páginas iniciais das matérias e reportagens, por se considerar que este era um espaço estratégico já consagrado para a elaboração e emissão de discursos, uma vez que ali, se introduzia o assunto, ao mesmo tempo em que se anunciava a abordagem que seria seguida.

0 contexto das reportagens era quase sempre o resultado de uma articulação direta das fotografias, a um título impresso em tipos grandes, aos subtítulos e legendas e ao próprio texto. A "foto manchete", era o elemento principal da reportagem e não raro ocupava quase todo o campo formado por duas páginas abertas da revista. 0 título pretendia conduzir a leitura inicial do conjunto, enquanto os outros elementos encarregavam-se de complementar as informações anunciadas.

Em se tratando de conteúdos a reportagem deveria ser abrangente, procurando atrair o interesse do maior número possível de leitores, de ambos os sexos, de idades e origens sociais variadas.

No plano do conteúdo a fotorreportagem em geral busca contar histórias que interessem a um grande número de leitores de diferentes sexos, idades e classes sociais. Para isso tanto vale abordar o cotidiano das pessoas comuns, que assim se sentem retratadas pela revista, como trazer para seus lares realidades inteiramente estranhas ao seu mundo, seja pelo exótico ou pela sofisticação, que igualmente as atrai. $\mathrm{Na}$ forma, a reportagem fotográfica procura situar o leitor no espaço e no tempo. É comum a abertura ter uma grande foto de impacto, que muitas vezes já dispõe o assunto geograficamente e/ou retrata os personagens da história. 0 encadeamento das imagens seguintes vai situar o leitor no tempo, ou através da construção de uma seqüência fotográfica que funciona como um pequeno filme, ou de imagens isoladas que, mesmo não formando uma série cronológica, vão sempre se dispor como imagens concatenadas. ${ }^{1}$

Dependendo da importância e do espaço destinado à veiculação do assunto, seu desenvolvimento continuava por um número variável de páginas, sempre amparadas em muitasfotografias. 0 conjunto ao final deveria apresentar-se como uma "história contada".

Em muitos casos, principalmente quando se tratava de reportagens menores, substituíase a foto manchete por um número padrão de 5 a 8 fotos divididas em duas páginas. Salvo raras exceções, a predominância dos elementos visuais, reduzia significativamente o espaço destinado a edição dos textos.

A escolha do estudo das fotografias deu-se em função de seu grande poder comunicativo do mundo contemporâneo. Parte significativa desta força advém da poderosa associação com o real que ela produz,

Graças a sua natureza físico-química - e hoje eletrônica - de registrar aspectos (selecionados) do real, tal qual estes de fato se parecem, a fotografia ganhou elevado status de credibilidade. Se por um lado, ela tem valor incontestável por proporcionar continuamente a todos, em todo o mundo, fragmentos visuais que informam das múltiplas atividades do homem e de suas ações sobre outros homens e sobre a $N$ atureza, por outro, ela sempre se prestou e sempre prestará aos mais interesseiros usos dirigidos. $^{2}$

1 SILVA, Silvana Louzada da. Fotojornalismo em revista: o fotojornalismo em 0 Cruzeiro e M anchete durante os governos de Juscelino Kubitschek e J oão Goulart. 2004. Dissertação (mestrado), U niversidade Federal Fluminense - UFF, Niterói. p.36.

2 KO SSOY, Boris. Realidades e ficções na trama fotográfica. São Paulo: Ateliê editorial, 2000. p. 19-20. 
A revista O Cruzeiro e o desenvolvimentismo: natureza e im agens do Brasil mo derno no governo JK

Tocando ao mesmo tempo no campo da imaginação,

[...] as imagens, no jogo de revelar e ocultar, constituem-se numa dialética da construção do mundo do homem e de seus dilemas: a vida, a doença e a morte. As imagens, contudo, não são dados, meras evidências indiciárias, mas construções imaginárias. Elas não se reduzem a evidências documentais, objetivas, elas são, enfim, simbolizações construídas histórica e socialmente. ${ }^{3}$

No que tange a abordagem fotográfica de um tema, as escolhas começam no próprio ato fotográfico, aí, "[...] o uso de um determinado tipo de lente, abertura do diafragma da câmara e o tempo de exposição da película à luz definem a imagem" ${ }^{4}$, assim como seu caráter informativo.Como se sabe, a inserção de fotografias nas páginas dos jornais, revistase outros tipos de publicação estrutura-se dentro de normas de apresentação gráfica e outras modalidades de intervenção técnica, produzindo, assim, o efeito de narrativas visuais

A fotografia utilizada na imprensa, o seu maior produtor, tem caráter e predominância informativa, nos jornais, mais do que nas revistas. É que os 'vazios' de textos encontram os seus complementos nas imagens e viceversa. Q ualquer notícia acompanhada de uma fotografia desperta mais interesse do que outra notícia sem imagem. ${ }^{5}$

Entre a simples idéia de uma foto, e sua publicação, ocorrem portanto várias operações. A mensagem jornalística é toda constituída por inúmeros procedimentos: “[...] a angulação define a condução do comportamento da mensagem, a edição determina o que deve ser publicado, em que página, com que título. A coleta de dados é 0 levantamento da notícia em si." ${ }^{6}$

Entende-se que o trabalho com as imagens na imprensa de circulação nacional permite, além de explorar seu potencial para a comunicação, perceber sensibilidades, projetos e várias outras características do período estudado, pois parte-se do princípio de que ela responde às demandas - política, social, cultural - do contexto em que foram produzidas, da mesma forma com que ajuda a estabelecê-las, transformando-se assim em veículo privilegiado para o estudo dos imaginários e da memória conforme postula Ana Cristina Teodoro da Silva,

[...] a imprensa de circulação nacional é uma das produtoras privilegiadas do imaginário da nação, é um dos lugares da memória. É rica em exemplos sobre como a memória histórica é gerada de acordo com os interesses do presente; no caso, de acordo com a imagem que calha ao meio de comunicação, no momento. Fenômenos associados à memória histórica estão presentes na urdidura deste trabalho: sua constituição através da importância investida em um fato; a associação do fato a palavras e imagens; a apropriação e recriação de um fato em um momento distinto; 0 lembrar e 0 esquecer e mesmo as associações afetivas geradas pela rememoração. ${ }^{7}$

Imprensa e Fotografia jornalística configuram-se, portanto, em fonte e objeto dessa pesquisa.

\footnotetext{
${ }^{3}$ DINIZ, Ariosvaldo da Silva. A iconografia do medo (imagens, imaginário e memória da cólera no século XIX). In: KO URY, M auro Guilherme Pinheiro (org.). Imagem e memória: ensaios em antropologia visual. Rio de Janeiro: Garamond, 2001. p. 115.

${ }^{4}$ NEIVA Jr, Eduardo. A Imagem. São Paulo: Ática,1994. p. 73.

5 LIM A, Ivan. A Fotografia é a sua linguagem. Rio de Janeiro: Espaço e Tempo, 1988. p. 17-18.

${ }^{6}$ BIAGI, O rivaldo Leme. 0 imaginário e a guerra da imprensa: um estudo sobre a cobertura realizada pela imprensa brasileira da Guerra do Vietnã na sua chamada "fase americana" (1964-1973). 1996. Dissertação (mestrado), U NICAM P, Campinas. P 22-23.

7 SILVA, Ana Cristina Teodoro da. O tempo e as imagens de mídia: capas de revistas como signo de um olhar contemporâneo. 2003. Tese (doutorado), UNESP, Campus de Assis. p. 17.
} 


\section{Natureza e desenvolvimento econômico}

Em meados da década de 1950, o Brasil vivia uma era de mudanças que atingia quase todos os aspectos da vida do país. Vargas se suicidara, e algum tempo depois assumia a presidência, por eleição, Juscelino Kubitschek, prometendo banir do país o subdesenvolvimento, 0 atraso e a pobreza, pregando 0 desenvolvimento por meio de um Plano de $M$ etas cientificamente traçado, que promoveria no país o avanço em ritmo de 50 anos em 5.

Para Warren Dean, tais concepções integravam-se em um contexto onde todos os atosem favor do desenvolvimento econômico - entre eles a devastação da natureza - eram justificáveis e pautavam-se na concepção de um objetivo maior, cujos resultados produziriam benefícios para toda a sociedade, esta articulação, criava um álibi, uma justificativa genérica que podia ser usada como argumento em discursos de qualquer ordem.

0 desenvolvimento, mais que uma política governamental, significava um programa social de enorme abrangência, energia e originalidade. A idéia de desenvolvimento econômico penetrava a consciência de cidadania, justificando cada ato de governo, e até de ditadura, e de extinção da natureza. Acima de tudo, nas representações do Estado, nos meios de comunicação e no imaginário popular, o desenvolvimentismo econômico se vinculava à erradicação da pobreza. ${ }^{8}$

0 desenvolvimentismo promoveu mudanças estruturais profundas na economia, mas foi atuando fundamentalmente na criação da imagem do Brasil como país do futuro, estimulando um anseio de modernização na sociedade - principalmente por meio da elaboração e da articulação de representações que enquadravam o projeto no padrão de modernidade da época - e na capacidade de fazer com que aqueles discursos obtivessem grande aceitação por parte da sociedade brasileira, que aquele projeto teve seu maior impacto.

Seguindo esta lógica, a construção de Brasília, por exemplo, ultrapassava em muito o enorme desafio de edificar uma nova e moderna capital em uma região distante do país, o feito, significava também naquele momento a superação atraso.

Os "Diários Associados", um conglomerado de mídia de propriedade de Assis Chateubriand, participaram - ainda que nem sempre de forma direta - na campanha eleitoral de Juscelino, integrando-se em seguida ao coro de propaganda do desenvolvimentismo. Com o passar dosanos, e o considerável sucesso alcançado pelo governo de JK, ampliaram as relações de interesses entre o presidente, interessado no apoio da mídia, e o poderoso empresário Chateubriand, interessado nas verbas publicitárias, nas vantagens pessoais e políticas que tais relações produziam ${ }^{9}$.

Pertencente ao grupo, a revista 0 Cruzeiro foi um dos mais importantes amplificadores daquele ideário, atuando diretamente nas propagandas das ações de governo e na divulgação das obras que se realizavam, mas foi principalmente com um discurso de

\footnotetext{
${ }^{8}$ DEAN, Warren. A ferro e fogo: a história e a devastação da mata atlântica brasileira. Tradução de Cid Knipel M oreira. São Paulo: Cia das Letras, 1996. p. 281.

9 Vale lembrar que o "apoio" oferecido por Chateubriand, não implicava necessariamente em qualquer tipo de concordância ou discordância com as políticas levadas a cabo por JK. Era comum inclusive que houvesse posições antagônicas dentro da própria equipe de repórters e editores da revista, que interferiam na elaboração das matérias, e que predominavam na sua condução as relações de puro interesse que freqüentemente forjados sob a tensão das chantagens políticas e trocas de favores.
} 
A revista O Cruzeiro e o desenvolvim entismo: natureza e im agens do Brasil mo derno no governo JK

evangelização modernizadora da sociedade, que mais promoveu o desenvolvimentismo, utilizando-se para isto da agilidade e da grande comunicabilidade proporcionadas pelo fotojornalismo

A modernização como uma meta, aparecia de forma mais direta nas peças publicitárias, na ênfase dos valores urbanos, na pregação da mecanização da agricultura, na defesa do aproveitamento das riquezas naturais regionais, ao mesmo tempo em que de maneira indireta, muitas reportagens sobre as praias cariocas - fotografadas de todos os ângulos e perspectivas - eram aproveitadas como veículo para a afirmação do um estilo de vida urbano da Cidade M aravilhosa. Assim, de várias formas e, com grande freqüência, faziase uma apologia daqueles valores, exaltandose a modernidade presente nos temas abordados, ou criticando neles a sua ausência.

\section{Natureza e desenvolvimento econômico}

No contexto em que o país viva naquele momento a questão da produção de energia compatível com as demandas de uma sociedade industrial apresentava-se como ponto nevrálgico.

A produção industrial brasileira baseavase em um modelo energético impróprio além de devastador - para sustentar as expectativas de crescimento do setor, principalmente porque tinha na lenha a sua grande matriz. M inas Gerais, por exemplo, com seu conglomerado de 12 usinas siderúrgicas instaladas em 1950,

[...] provocavam a derrubada de $2650 \mathrm{~km} 2$ de matas. [...]. Um importante setor metalúrgico estava em crescimento [...]. Embora alguns dos fornos fossem elétricos, a maioria necessitava de cargas de lenha [...] Em 1950, a demanda anual de matas das indústrias metalúrgicas nestes dois estados e no Rio de Janeiro pode ter chegado a 140 km2. [...] Estima-se que, em 1948, lenha e carvão vegetal representavam $79 \%$ de toda a energia consumida no Brasil [...]. No sudeste, a queima de lenha e carvão por certo não era menor que $50 \%$ do consumo de combustível, apesar de volume significativo na geração de energia hidrelétrica e do aumento da capacidade da região de importar combustíveis fósseis. ${ }^{10}$

A tensão gerada por tal realidade, instituía um paradoxo entre discursos e práticas, pois se de um lado a necessidade de superação desta situação serviu como argumento em favor da modernização, municiando a propaganda que associava aquela condição ao atraso e mesmo à escravidão, de outro mesmo depois de reiteradas constatações do problema e da edição de diversas leis de proteção das reservas de matas nas décadas anteriores - não se fazia praticamente nada de efetivo para preservar as florestas, principalmente a mata atlântica de tal devastação, ainda que fosse com o objetivo estratégico de se garantir as reservas desse tipo de insumo, para o uso das futuras gerações, perspectiva que inspirava discursos protecionistas desde o final do século XIX.

Refletindo um problema estrutural do desenvolvimento da economia capitalista no Brasil, para Warren Dean essa condição derivava da própria história da evolução dos setores energéticos no país, segundo ele,

“O Brasil ingressou na era Industrial
extremamente carente de um de seus pré-
requisitos: combustíveis fósseis de
hidrocarbono. Como a Suécia e a Itália, o
Brasil postergou a aplicação plena das
técnicas industriais até a inserção do dínamo
elétrico. [...] Mas a energia elétrica era, na

${ }^{10}$ DEAN, op. cit., p. 268- 269. 
época, de difícil aplicação econômica a muitas demandas a que os combustíveis fósseis atendiam em outros países." 11

Circulando por diversas esferas da sociedade, 0 assunto freqüentava as páginas de variados tipos de publicação. A tuando na interlocução destes problemas desde meados da década de 1940, por exemplo a chamada "imprensa nacionalista" colaborava para manter os temas relativos à produção de energia no cerne dos debates. Naqueles promovidos pela Revista do Clube Militar, quando as discussões tratavam de minerais estratégicos como a M onazita e fontes de energia como a Eletricidade e Petróleo, predominava uma concepção de que a sua produção ou exploração, deveriam ser nacionalizadas, segundo, Plínio Ramos de Abreu,

É também publicada conferência do engenheiro Rodrigues M onteiro, realizada em 05 de abril de 1950 no auditório do Clube M ilitar, sobre 'o problema da eletricidade no Brasil' reprovando privilégios concedidos à Light, que exercia monopólio do setor no eixo Rio - São Paulo. ${ }^{12}$

Estes entre outros itens considerados estratégicos, faziam parte de um extenso Programa de $M$ etas que geravam propostas e planos de ação para desenvolver a economia do país. Fundindo-se ao ideário desenvolvimentista, 0 assunto circula nas páginas de 0 Cruzeiro, eo descompasso entre produção e demanda deste insumo básico para o desenvolvimento industrial, acentuava sua importância. As reportagens sobre produção de energia, são representadas na revista principalmente pela exploração do petróleo, e geração de energia hidrelétrica alicerces da chamada indústria de base recebeu também atenção a criação de empresas de extração e processamento de minérios..

Não constituindo objeto novo na fotografia, a abordagem da natureza como "Natureza Produtiva", foi trabalhada por Vânia Carneiro de Carvalho ${ }^{13}$, em séries de pinturas e de fotografias do Brasil do século XIX.

Sobre as imagens da produção, a autora contemplaque,

A natureza neste caso adquire interesse fotográfico na medida em que está engajada no processo produtivo. A fotografia procura dar conta de todo o circuito de produção fazenda/ferrovia/porto - no qual a ferrovia figura como o símbolo mais expressivo da modernização. Além de cumprir uma das etapas essenciais ao capitalismo, isto é, agilizar a circulação de mercadorias, a ferrovia significa a presença da indústria em um país basicamente agrário. Ela realiza imaginariamente o desejo de participação dos valores gerados nas economias centrais, com as quais procura criar vínculos abolindo o "exótico" e o provinciano da sua natureza, transformando-a em imagem do progresso, do domínio do processo produtivo, em prova documental da prosperidade que 0 país poderia oferecer; em resumo, transformando a natureza em imagemmercadoria. ${ }^{14}$

A comparação do material imagético encontrado em 0 Cruzeiro - analisada a partir das tipologias estabelecidas - permite perceber em meados do século XX a

${ }^{11}$ Idem, p. 266.

${ }^{12}$ RAM O S, Plínio de A breu. A imprensa nacionalista no Brasil. In: ABREU, Alzira. (org.) A imprensa em transição: o jornalismo brasileiro nos anos 50. Rio de Janeiro: FGV, 1996. p. 82.

${ }^{13}$ CARVALHO, Vânia Carneiro de. A representação da natureza na pintura e na fotografia brasileiras do século XIX. In: FABRIS, Annateresa (org.). Fotografia: usos e funções no século XIX. São Paulo: Editora da U niversidade São Paulo, 1991. (Coleção texto $\&$ arte; vol.3).p. $198-261$

${ }^{14}$ Id. Ibid., p. 217. 
permanência da abordagem, embora relativamente modificada pelo uso de novos equipamentosfotográficos e pela linguagem introduzida pelo fotojornalismo.

$\mathrm{Na}$ cobertura da construção das hidrelétricas, dadas as dimensões em geral monumentais das obras, as fotografias aéreas - técnica que agrega indiretamente outros significados à imagem produzida -, constituíram-se em artifício dos mais usados na medida em que permitiam captar a proporção das obras em relação ao entorno. 0 uso desta técnica, documentava o processo de transformação da natureza pelo homem, a partir de um ângulo privilegiado, que ajudava inclusive a caracterizar o esforço e 0 investimento envolvidos.

Já na primeira série de revistas pesquisada correspondente ao ano de 1954, detecta-se a presença do tema, seja na veiculação de uma propaganda institucional da empresa elétrica Light, na forma de um artigo sobre a construção da usina subterrânea "Nilo Peçanha"15 - situada no estado do Rio de Janeiro - ou em reportagens como "M ais M eio $M$ ilhão de Kilowatts a Serviço do Brasil|"16, sobre a inauguração da mesma usina.

No período subseqüente, reportagens sobre outras usinas em processo de construção ou modernização, procuravam denotar o empenho dos governadores de vários estados da união investindo em infraestruturas que ajudassem a colocar aquelas regiões na vanguarda do processo de industrialização. Nesse sentido, o caso de $M$ inas Gerais durante o governo de JK (19511955) foi emblemático, como a base de sua administração seria: energia e transporte [...]. Tendo como meta prioritária retirar $M$ inas da condição de estado agro-pastoril e lançá-lo na fase da industrialização, a despeito de uma situação financeira precária, marcada por uma dívida volumosa, Juscelino desdobrou o plano inicial em duas etapas, A) eletrificação e estradas, e B) industrialização. 0 plano relativo à energia elétrica, em linhas gerais, previa 0 incentivo à iniciativa privada $[. ..] .^{17}$

"Culpa de JK: M inas dá Choque"18, sobre a inauguração de uma usina, na cidade mineira de Itutinga em 1956, torna-se oportunidade perfeita para associar o vanguardismo de JK ex-governador de M inas Gerais, com as suas ações, não menos arrojadas, já como presidente recém eleito.

O cupando quase todo o espaço das duas páginas do seu campo de abertura, uma tomada aérea permite estabelecer um contraste entre a obra - no caso uma enorme barragem - e a paisagem do entorno. No centro do foco, as instalações da usina, representadas pelo grande muro de concreto, e, ao fundo, parte de um lago que o extraquadro sugere enorme, destacam a imponência da obra. Atuando como escala, prédios e outras instalações de grande porte apequenam-se ao lado dos paredões por onde a água começa a verter. Inaugurando simbolicamente o funcionamento da usina em uma foto menor ao lado, JK posa ligando uma chave, que iniciava seu funcionamento.

Fotografar o presidente realizando aquele ato reforçava seu papel de homem realizador, uma vez que entregava uma grande e importante obra, o uso do adjetivo "criador de energia" por sua vez associava-o ao desenvolvimento do país.

${ }^{15} \mathrm{O}$ Cruzeiro 24/04/1954. Propaganda institucional da empresa Light. p.93.

${ }^{16} 0$ Cruzeiro 11/12 /1954. Textos e fotos de Alceu Pereira. p.124-125.

${ }^{17}$ ABREU , Alzira Alves de...[et al.]. Dicionário Histórico-Biográfico Brasileiro pós 1930. Vol. III. Rio de Janeiro: Editora FGV;CPDO C, 2001.p.4821.

${ }^{18}$ O Cruzeiro 10/11 /1956. Reportagem de O lavo Drummond. p.12 e 13. 
No Estado de São Paulo, as estratégias não eram muito diferentes, lá

[...] o governo Jânio [Q uadros] conseguiu também [...] projetar diversas usinas hidrelétricas, realizar obras na usina de Salto Grande, Limoeiro, Euclides da Cunha, Barra bonita, Jurumirim e Graminha [..], o que representou considerável aumento nas obras ligadas ao aumento da produção de energia. ${ }^{19}$

$\mathrm{Na}$ reportagem sobre a construção da usina de Salto Grande, no interior do Estado, o título ordenava: “Tire o Chapéu a São Paulo: civilização da eletricidade". ${ }^{20}$ (Figura 1)

Repetindo mais uma vez o modelo, novamente uma foto aérea, ocupava cerca de dois terços das duas páginas iniciais da reportagem, nela uma série de obras, em cujo centro se destaca um grande lago represado por uma barragem de iguais proporções. $O$ utros elementos como estradas, pontes, e estruturas indefinidas de concreto em meio a montes de terra revolvida, complementam a cena, ao mesmo tempo que servem de escala para o tamanho da represa.

Ao lado, uma foto menor mostra uma espécie de rotor, suspenso por um gancho. 0 comentário do box informa que "As gigantescas turbinas de Salto Grande estão colocadas e aptas a rodar."

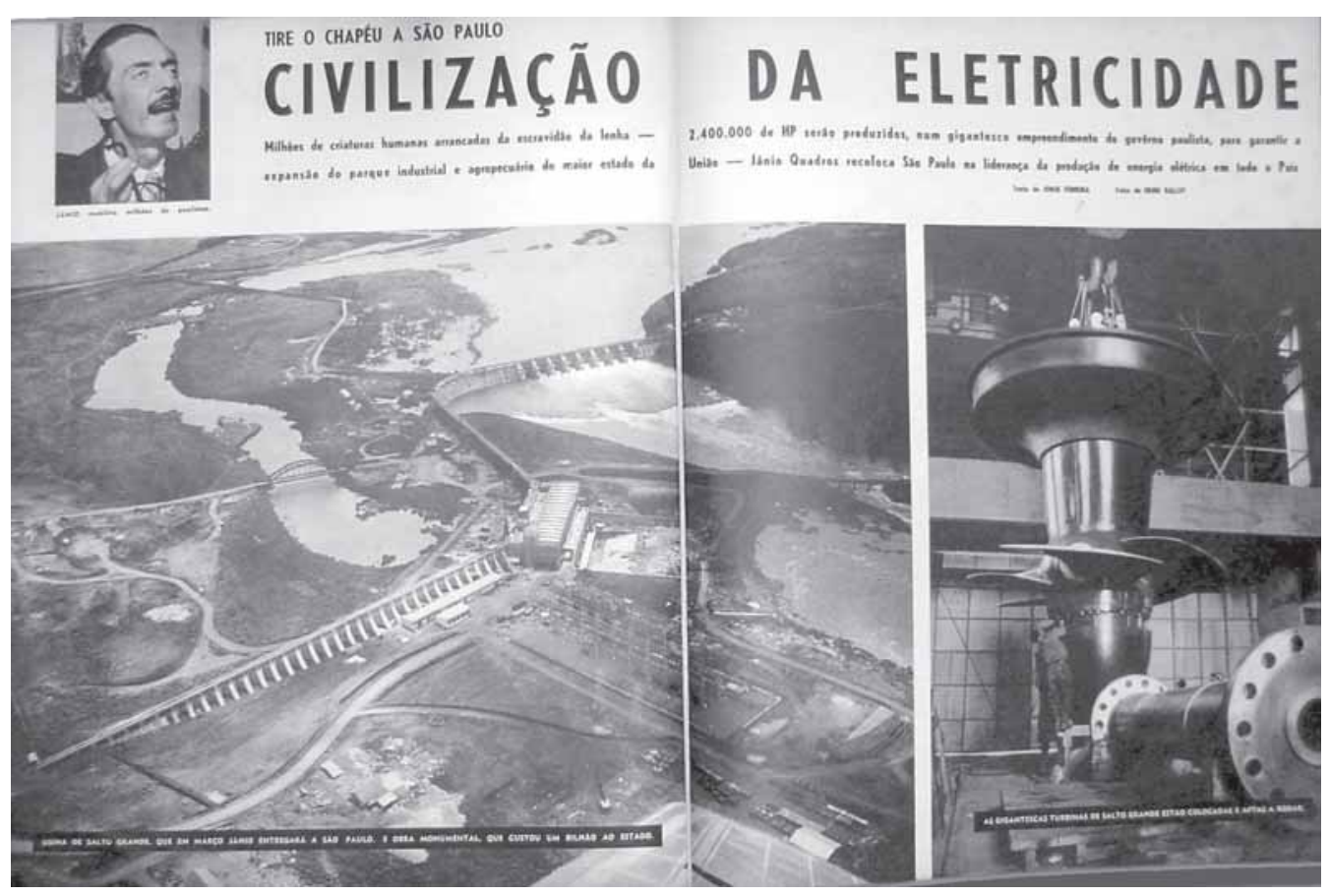

Figura 1 - 0 Cruzeiro de 15/02/1958

\footnotetext{
${ }^{19}$ ABREU , 2001, op. cit., p. 2955.Verbete Jânio Q uadros.

${ }^{20} \mathrm{O}$ Cruzeiro 15/02/1958. Textos de Jorge Ferreira e fotos de Henri Ballot. p.88-101.
} 
Da forma como foram apresentadas, 0 tamanho das "gigantescas turbinas", podem ser deduzidas: tanto pelo contrataste com as instalações formadas por um prédio de dois andares, quanto pela associação com a outra imagem.

O subtítulo assinala um sentido de libertação por efeito da modernidade, baseada no direito de consumir eletricidade, descrita como uma energia socialmente redentora, ao passo que a autoria é creditada ao governador, Jânio Q uadros,

M ilhões de criaturas humanas arrancadas da escravidão da lenha - 2.400.000 HP serão produzidos, num gigantesco empreendi- mento do governo paulista, para garantir a expansão do parque industrial e agropecuário do maior estado da União - Jânio Quadros recoloca São Paulo na liderança da produção da energia elétrica em todo o país.

A legenda de uma pequena foto do tipo "boneco"21 do governador reforça este sentido, afirmando que "Jânio reabilita milhões de paulistas."

Em 7 de novembro de 1959, a revista veiculava uma foto da construção da usina hidrelétrica de Furnas, acompanhada da significativa manchete: "23 discursos e um só tema em almoço tropical: os KW do Rio Grande, que modificarão o retrato econômico do País: furnas: Brasil de amanhã"22.(Figura 2)

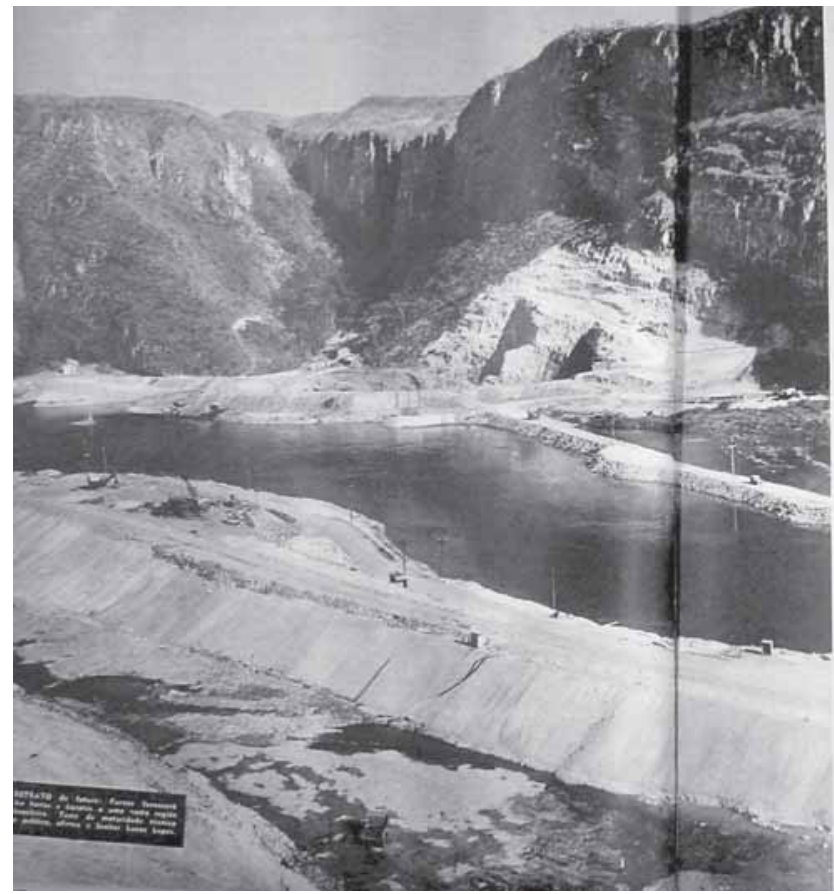

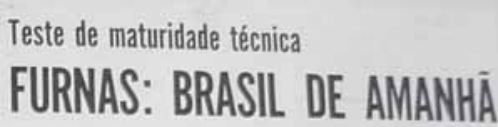

23 discursos e un 56 tema em almâço tropical: os kn ta Rio Grande, que modificarão o retrato economico to Pais.

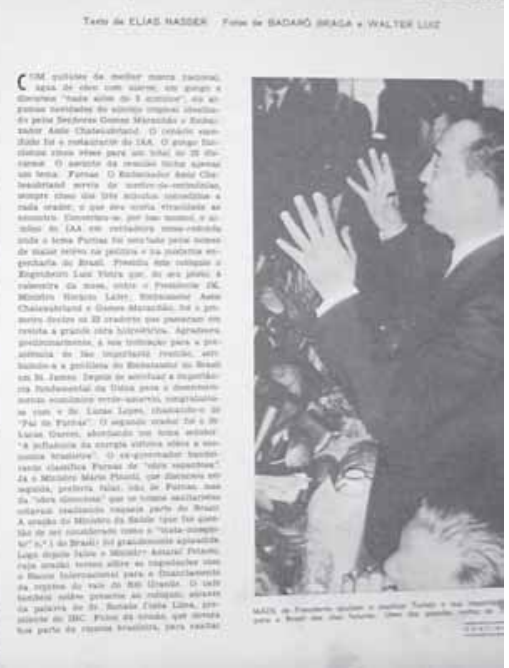

Figura 2 - 0 Cruzeiro de 07/11/1959

\footnotetext{
${ }^{21}$ Designação utilizada para fotos de rosto, em geral publicadas em pequenos formatos, que ajudam a inserir personagens nas reportagens, integrando-os como autores, vítimas, ou simplesmente participantes do assunto reportado.

${ }^{22} \mathrm{O}$ Cruzeiro 07/11/1959. Textos de Elias Nasser e fotos de Badaró Braga e Walter Luiz . p.46-51.
} 
A natureza é representada em terceiro plano por um imenso vale coberto por restos de mata, que a imagem sugere, ainda estavam em processo de derrubada, o plano intermediário funde-se com o primeiro plano, mostrando obras de um grande lago em formação, que contrasta em tamanho com 0 vale. $O$ utros elementos que compõe a imagem, tais como caminhões, dragas, postes, construções, equipamentos pesados e estruturas de grande porte, no contexto, ficam do tamanho de alfinetes e botões de camisas. A legenda referente a essa foto avisa: "Retrato do futuro: Furnas fornecerá Kw fartos e baratos a uma vasta região brasileira. Teste de maturidade técnica e política, afirma 0 senhor Lucas Lopes".

A foto panorâmica tirada de um lugar alto, a grande distância da cena retratada cria uma paisagem baseada em contrastes. Natureza indomada, representada de forma colossal de um lado; de outro, homem, representado por máquinas, jipes, caminhões e construções, símbolos da racionalidade e do engenho humanos, em uma luta para que essas forças naturais fossem domadas.

O cupando parte do terço restante do campo, uma foto mostra Juscelino discursando com as mãos abertas. A legenda interpreta este ato como a expressão do gigantismo envolvido na construção da hidrelétrica afirmando que só as: “ $M$ ãos de Presidente ajudam a explicar Furnas para 0 Brasil dos dias futuros. U ma das grandes metas deJK". O u seja, somente um metafórico gesto de mãos abertas para explicar algo tão grande.

A monumentalidade, que as imagens evocam, reforçadas pelos títulos em questão, associa diretamente a Natureza com "a geração de Kilowatts" que, deveriam ser usados enquanto o meio de criar o desenvolvimento econômico.

Um importante elemento, presente no material so bre a construção de hidrelétricas, como pode ser visto, é o vínculo das figuras dos administradores públicos e as obras e com seus resultados benéficos.

Esse tipo de relação poderá ser encontrado em muitas outras representações que multiplicando praticamente a mesma abordagem.

0 tema da construção de estradas é outro que, caracteriza-se de maneira importante no período, constituindo uma série de reportagens que transformam um assunto cotidiano em veiculo de idéias e discursos sobre o desbravamento das selvas, a modernidade e a expansão nacional.

No período estudado, a primeira reportagem a respeito circulou em $1954 \mathrm{com}$

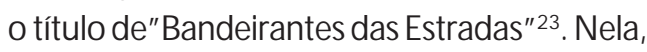
a revista faz um libelo aos motoristas, tratados como heróis anônimos: "O nome, não importa, eles são os motoristas de estradas que carregam "o sangue do progresso "que trafega por "artérias empoeiradas". As estradas são descritas como lugares por onde corre a riqueza do país, e ao mesmo tempo como lugares perigosos. Os motoristas, "heróis anônimos" são descritos como figuras de personalidade ímpar, ligados a difícil profissão, como que a um vício "[...] apesar de tudo, como marinheiros, eles estão presos a sua profissão, como a um vício." Eram os profissionais do asfalto que além de dirigir, consertavam e socorriam caminhões tombadose atolados.

As precárias condições das estradas tornam-se freqüentemente um tipo de sujeito oculto no discurso das fotos e legendas por meio de metáforas, tocando muito

${ }^{23} \mathrm{O}$ Cruzeiro 09/10/1954. Texto e fotos de J oão M artins. p. 74 e 75. 
indiretamente no assunto, como foi o caso de,"Estradas do Diabo"24.

Ao título curioso o texto dá continuidade, denunciando que tal estatuto definia também as condiç̧̃̃es em outros lugares do país.

Sua Exa., o Doutor Belzebu, saiu lá das profundezas e foi amassar as estradas de rodagem lá do interior de Goiás. Aliás, as de $M$ inas Gerais devem entrar, também, no âmago dessa sinceridade.

Q uestão retomada em reportagem específica cerca de um mês depois, em "Rio Belo Horizonte em sete horas. Respira M inas Gerais"25 (Figura 3). Constituída por três fotos em duas meias páginas que dividem com 0 texto o espaço da reportagem, tinha como foco principal um viaduto, construído em uma estrada que liga os estados de M inas Geraise Rio de Janeiro. Apresentado como parte de um extenso conjunto obras congêneres composto por "[...] nada menos que 757 metros de obras de arte foram construídas pelo atual governo no ano passado. Entre essas obras, a mais importante é o Viaduto do Córrego das Almas", composto por mais de 250 metros de comprimento, o viaduto aparece enquanto uma peça vital, um importante elo que permitiria funcionamento de toda a corrente, representada pela moderna estrada asfaltada, retratada em uma da fotos.

As duas outras fotos que retratam 0 viaduto foram tomadas de uma perspectiva lateral, à distância, de forma a aproveitar ângulos que valorizassem a engenhosa ponte, construída em curva, que desta perspectiva parece encravar-se na paisagem. N este caso a natureza tornava-se a escala para o tamanho, e para a complexidade da tarefa

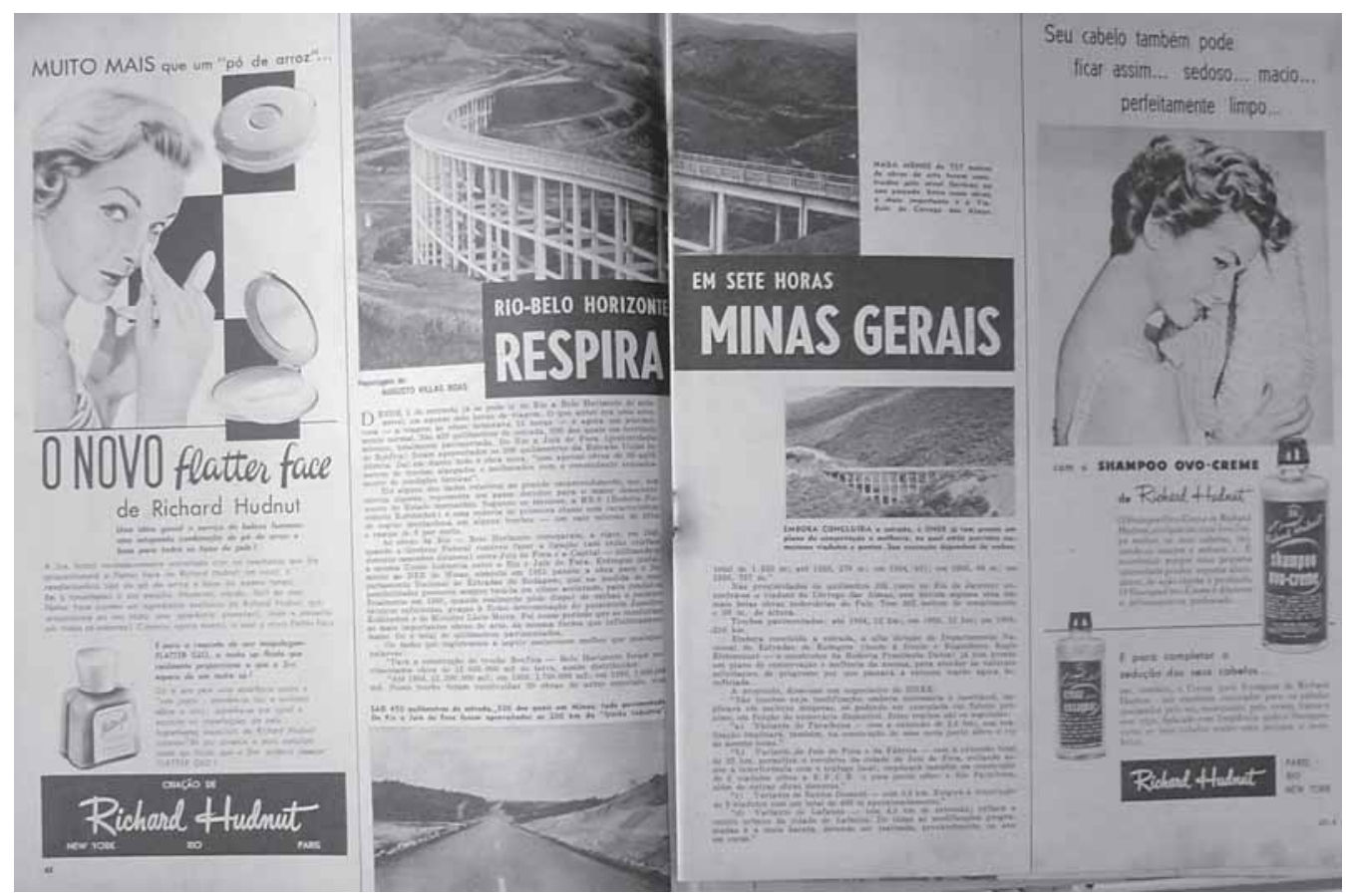

Figura 3 - 0 Cruzeiro de 02/02/1957

${ }^{24} \mathrm{O}$ Cruzeiro 04/12/1954. Reportagem sem autoria definida e Fotos de Keffel Filho. p. 82D.
${ }^{25} \mathrm{O}$ Cruzeiro 02/02/1957. Reportagem de Augusto Villas Boas. p.42 e 42A 
realizada, ajudando o leitor perceber as dificuldades geográficas que foram vencidas para a sua execução. ${ }^{26}$

Segundo as legendas, a rodovia representava um avanço para os estados ligados por ela, "São 450 quilômetros de estrada, 300 deles em Minas, tudo pavimentado. Do Rio a Juiz de Fora foram aproveitados os 200 km da U nião Indústria.", etambém integravam parte do corpo de obras iniciadas pelo presidente Juscelino Kubitschek, quando ainda governador do estado de M inas Gerais, poucos anos antes.

No final de 1958, a construção da Belém Brasília produziria uma reportagem intitulada "Monstros de Aço Abrem a Rota BelémBrasília"27, e com ela se inaugurava uma subsérie sobre a construção de estradas em meio a selvas.

Começava a se constituir na revista um modelo épico de esforço hercúleo na construção de rodovias como a Belém-Brasília e mesmo a BR2 - que teve alguns trechos construídos em regiões de selva - onde "O homem nunca havia pisado".

O início desse hino de louvor público ao progresso mostrava grandes máquinas de terraplanagem, fotografadas em um plano muito fechado, de forma que suas características próprias de tratores de esteira estacionados um ao lado do outro se deformassem, criando uma surreal mistura de elementos. Complementando a cena, um homem posicionado, ao canto da foto, parece fugir em pânico daquelas monstruosidades.

0 utro texto legenda da reportagem reforça a concepção, relacionando o desmatamento produzido pela abertura da estrada a um ato de progresso,

A selva amazônica que desafiava o progresso
desde os tempos do Grão-Pará, está sendo
afinal dominada pela máquina e pelo homem.
Centenas de quilô metros de modernas
rodovias cortam a selva bruta, transmitindo
o fluxo de civilização ao "hinterland" caboclo,
escravizado pelo mono-extrativismo da
borracha. U m punhado de homens está
mudando a fisionomia da Amazônia para
integrá-la na unidade geográfica e econômica
do país. ${ }^{28}$

Dando seqüência à divulgação desse modelo de modernidade, naspáginas seguintes um subtítulo informa, por sua vez, ao leitor que "O s veículos poderão correr a 100 ou $120 \mathrm{Km}$ por hora em pleno coração da Amazônia", pregando que a partir de então se instaurava o direito pleno de ser moderno pois brasileiros adquiriam o poder de deslizar sobre quatro rodas pelo meio da floresta, até então tida como inóspita e indomada porque inacessível.

A partir de 1959, institui-se um período pródigo na cobertura do assunto, mas talvez, mais importante que a quantidade de artigos veiculados, tenha sido a introdução de outras modalidades de discursos. É certo que elementos que já integram o imaginário da construção das estradas continuarão presentes, mas outros se incorporam e, devido a sua repetição, permitem entrever novos conteúdos.

A reportagem "Nossa Senhora da Selva Abençoa a Belém Brasília", (Figura 4) por exemplo, agrega o caráter religioso ao tema. Sobre esta curiosa "aparição", em lugar tão remoto, o texto comenta que em certa ocasião,

\footnotetext{
${ }^{26} \mathrm{~A}$ mesma análise pode ser aplicada à foto menor.

${ }^{27}$ O Cruzeiro $11 / 10 / 1958$. Texto de Arlindo Silva e fotos de U biratan de Lemos.

${ }^{28}$ Idem p.60
} 


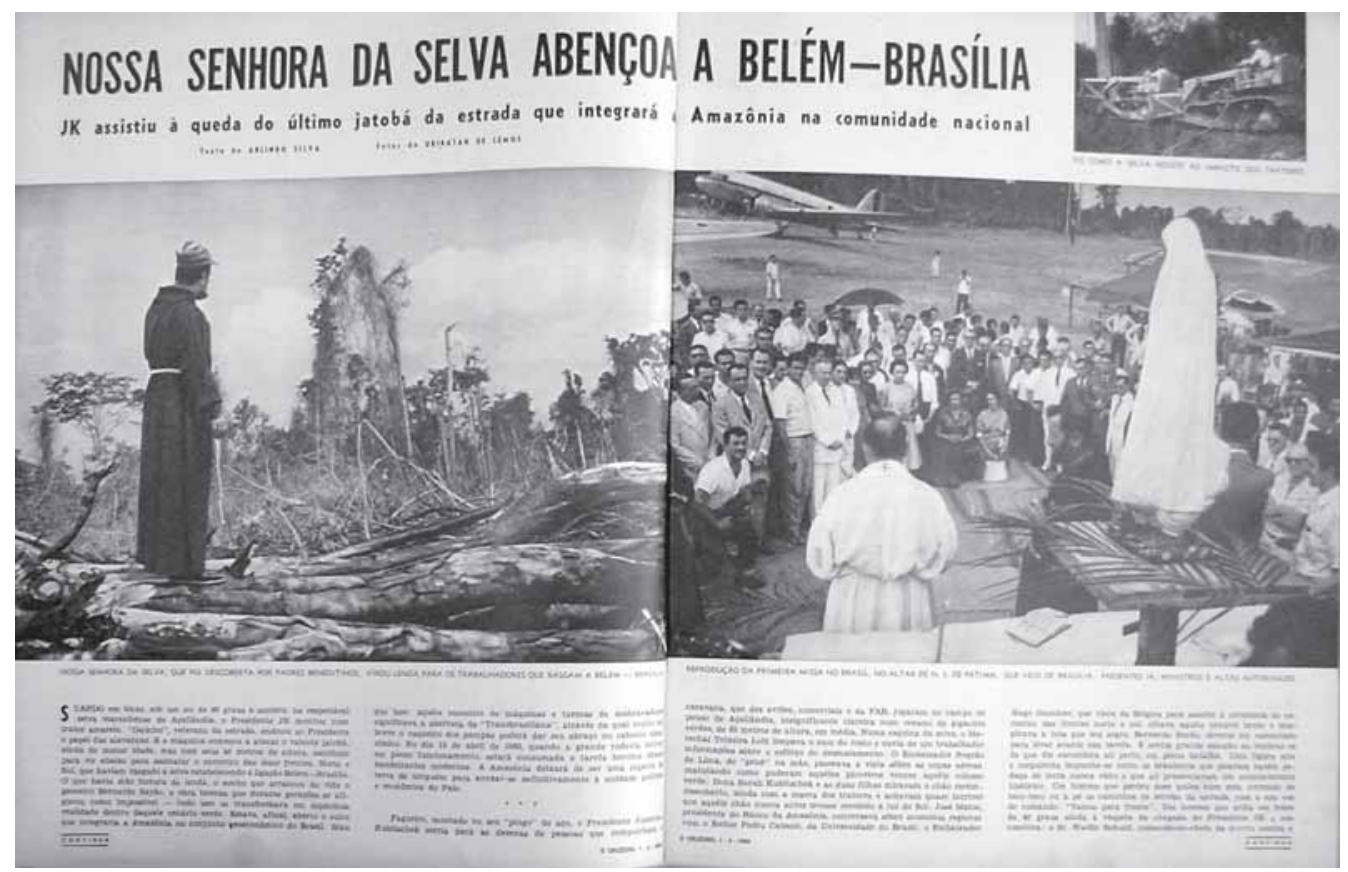

Figura 4 - O Cruzeiro de 07/03/1959

[...] dois sacerdotes beneditinos de Brasília, em suas andanças pelas cercanias de Açailândia, encontraram um grupo de pequenas árvores, cobertas de cipós e orquídeas, cuja silhueta lembra a imagem da virgem M aria com o M enino Jesus ao colo. Viram naquela figura, criada pela natureza, uma manifestação da presença divina entre aquele exército de homens que passavam sacrifícios, apanhavam enfermidades na mata. Suportavam a tortura da saudade e o martírio dos mosquitos. Era uma inspiração para aqueles trabalhadores denodados que tinham deixado longe seus lares, suas esposas e seus filhos. Voltando ao acampamento, contaram seu singular achado e, em seguida, turmas de trabalhadores dirigiram-se até a imagem da Virgem e diante dela tiraram seus chapéus de palha e persignaram-se. Nossa senhora da Selva foi o nome que os humildes e rústicos deram à imagem esculpida pela natureza em plena mata e a elegeram padroeira da estrada. ${ }^{29}$

Elaborado desta maneira, o texto sugere que as forças divinas apóiam a empreitada, oferecendo, através da natureza, um curioso objeto de culto cristão aos humildes "[...] caboclos com seus chapéus de palha". M eio "aparecida", N ossa Senhora da Selva tornase fonte de esperança e conforto para os trabalhadores braçais envolvidos.

A outra foto constrói também uma imagem do religioso, e, embora as bênçãos à estrada venham da silhueta vegetal, conforme indicado, a estátua que servirá ao culto que se realizou será uma imagem feita pelas mãos do homem, artesanal ou industrialmente, de algum material cerâmico. Representação da "mais civilizada" fé, por assim dizer, foi trazida de Brasília para a reprodução do evento da "Primeira M issa". Defronte a um altar, um sacerdote vestido de branco oficia o culto, enquanto um grupo de pessoas, todas em trajes sociais, algumas de joelhos assistia. Segundo a legenda "[...] são [...]JK, ministros e altas autoridades".

${ }^{29} \mathrm{O}$ Cruzeiro 07/03/1959. Texto de Arlindo Silva e fotos de U biratan de Lemos. p. 40. 
Assim duas religiosidades distintas manifestam-se no mesmo espaço natural. U ma completamente vinculada a ele, emanando mesmo dele, serve aos simples. U ma maioria formada por milhares de trabalhadores anônimos "N ossa Senhora da Selva, que foi descoberta por padres beneditinos, virou lenda para os trabalhadores braçais que rasgam a Belém-Brasília.".

Os outros envolvidos, o presidente, os ministros e "altas autoridades", são os que formam um grupo especial, que também presta suas homenagens, mas a Nossa Senhora de Fátima, representada por uma imagem tradicional, feita, de cerâmica.

O s discursos elaborados a partir daí ora articulam o momento a uma versão heróica da história da colonização do Brasil, ora reafirmam a batalha contra a selva, os operários, por exemplo, formam: “U ma Legião de Bravos que Faza História do Brasil no Inferno Verde", enquanto um intelectual presente discursa "[...] numa clareira aberta na mata, que está sendo usada como campo de pouso, o Reitor Pedro Calmon rememorou feitos heróicos da colonização do Brasil". Em outro momento, o texto-legenda comenta a foto aérea tomada da estrada, destacando 0 "Trabalho de Bandeirantes" anunciava: "[...] eis um trecho da Belém-Brasília, um sulco aberto num oceano verde. Através dela 0 vaqueiro dos pampas abraçará o caboclo amazônico.". Formando uma linha de força vertical, a estrada aparece como uma estreita clareira em meio á mata.

Já o presidente - personagem cujas palavras chegam ao leitor por intermédio do repórter, posicionado como testemunha ocular da história - segundo a versão da revista, comemora o feito de integração de áreas antes inóspitas, ao Brasil moderno: "[...]VIVA O BRASIL, disse JK ao hastear a bandeira na selva.", ato civilizador por excelência, ao realizá-lo, Juscelino simbolicamente anexava ao país uma nova região.

Embora esta já integrasse formalmente a nação, no nível do imaginário ocupava nela um lugar obscuro, desconhecido e pouco definido, porque pouco habitado ou totalmente desabitado, longe portanto da civilização e conseqüentemente do alcance da modernidade.

Ao fundar-se a estrada que cortava a selva, colocava-se fim às sombras que envolviam "terras onde nunca tocara a luz do sol", e na medida em que se desenvolviam projetos de colonização das margens da rodovia - implementados muitas vezes com o assentamento dos próprios operários que a construíam -, povoava-se o deserto, impedindo-se com isto que elas se tornassem dutos isolados de civilização em meio à imensidão de matas selvagens. O u seja, tratava-se de consumar a apropriação da selva para além da construção das rodovias.

Em outro momento, JK aparece, pilotando um trator de esteira, arremete contra uma árvore, experimentando pessoalmente, ao lado do mais humilde operário, o sabor e a proclamada dureza da batalha contra a selva. Logo acima, a imagem mostra uma grande árvore, e entre elas o texto: “O garboso jatobá resistiu 45 minutos ao trator presidencial e exigiu duas máquinas possantes para que tombasse. Eis um exemplo da dureza da luta.".

O subtítulo comenta que há um preço nessa luta, que homens morreram nesse embate: "A Floresta Virgem vingou-se de seus mais ousados conquistadores". Sob uma outra foto há o seguinte comentário: Foto da BelémBrasília. Sayão e Rui de Almeida mortos em ação. JK e Waldir Bohuid, comandante da batalha contra a selva." 


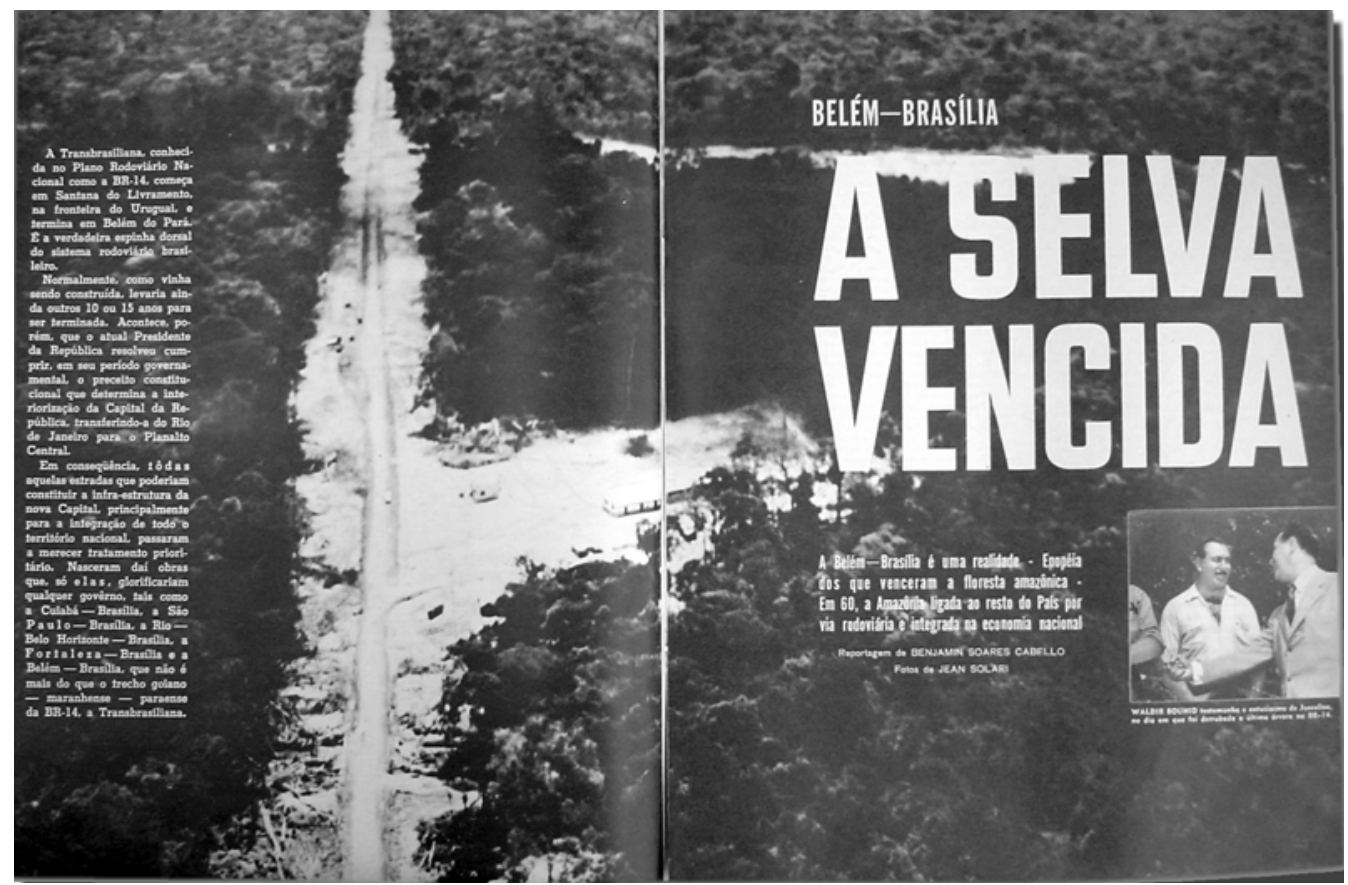

Figura 5 - 0 Cruzeiro de 12/09/1959

Nada melhor para definir uma situação de guerra que o uso de uma terminologia militar; que transformava aqueles homens, de engenheiros mortos acidentalmente, em comandantes mortos no campo de batalha.

A escolha dessas palavras, também reenquadra o empreendimento na categoria de guerra do homem contra a natureza, nessas reportagens a forma como o assunto foi abordado fornece bons indícios do imaginário sobre o assunto no período. Produzidos em meados da década de 1950, estes discursos integram o tema às idéias correntes na época sobre a necessidade de apropriação e integração dasáreas "selvagens" à civilização, realçando uma das características mais poderosas do imaginário, agregar valores e discursos de várias épocas e lugares, podendo atualizá-los dinamicamente, a partir dos anseios e valores presentes na sociedade.

Ainda em setembro do mesmo ano, vazado em grandes letras brancas sobre uma foto aérea, muito escura, que sangra duas páginas, o título “Belém-Brasília: a selva vencida" ${ }^{30}$ (ver figura 5 ) retoma 0 assunto. Em meio a uma densa vegetação, a estrada é representada por uma fenda larga e clara, um trilho totalmente desmatado em meio à selva, ao lado da qual é possível ver uma pequena clareira em que alguns casebres servem de base de operações para as atividades dos engenheiros e operários. Abaixo, outra foto menor mostra quando "W haldir Bohund testemunha o entusiasmo de JK no dia em que foi derrubada a última árvore da BR 14". Logo abaixo, o texto-

${ }^{30} \mathrm{O}$ Cruzeiro 12/09/1959. Reportagem de Benjamin Soares Cabello e Fotos de Jean Solari. p. 64-72. 
legenda confirma a vitória do homem, sua conquista em uma luta de titãs e o benefício que sua construção trará à região, “A BelémBrasília é uma realidade - Epopéia daqueles que venceram a Floresta amazônica. Em 60, a Amazônia ligada ao resto do País por via rodoviária e integrada na economia nacional."

0 uso de fotos aéreas, não é recurso novo em 0 Cruzeiro, como já foi visto. N este caso específico, porém, não é no destaque da grandiosidade da própria obra que reside o valor mais intrínseco do seu uso - como ocorria com as fotografias de construções de usinas hidrelétricas, mas exatamente na produção do efeito contrário, da valorização do contexto inóspito em que ela se insere.

Pode-se perceber que no que diz respeito à qualidade dos enunciados nos títulos é uma paulatina mudança, da denúncia, da caracterização do assunto como "Bandeirantes das Estradas" e "Estradas do Diabo" para um estágio intermediário com dizeres como Respira M inas Gerais e por fim "A Selva Vencida". Por comparação, nota-se que eles se modificam significativamente do que eram no período anterior e posterior a 1956 a partir de quando passam a ser encontradas inúmeras alusões ao heroísmo dos comandantes da batalha contra a selva que tinha as operações de logística dirigidas do interior de um avião por um coronel do exército, dos engenheiros- dois deles mortos por árvores que caíam - e aos soldados, trabalhadores braçais, em geral nordestinos que enfrentavam toda sorte de dificuldades, de machados na mão e na pilotagem das motoniveladoras, para fazer avançar as obras no ritmo de quilômetros por dia.

\section{Considerações finais}

Para concluir, gostaria de dizer que por meio dos exemplos citados aqui - que não passam de indícios do volume e da proporção com que reincidem as diversas imagens do país - é possível perceber na revista 0 Cruzeiro do período, a elaboração de modelos para o Brasil e para os brasileiros, alguns direta ou indiretamente definidos como exemplos a serem seguido e outros a serem evitados. Neste contexto a Natureza, com muita freqüência, transformava-se em veículo ou suporte dos discursos que se criavam.

O tema do desenvolvimento econômico foi sistematicamente representado nas páginas da revista. Aparecendo das mais variadas formas, materializa-se simultaneamente nas propagandas e na cobertura de um sem número de assuntos, entre eles o das construções de usinas hidrelétricas e das estradas que cortavam as selvas, discutidas aqui.

Associando padrões, modelos e valores, das mais variadas formas, valendo-se de uma vasta gama de imagens de todos os tipos, 0 Cruzeiro ajudava a criar 0 Desenvolvimentismo, participando ativamente da difusão de um modelo. Se em muitos momentos a revista pegou carona na grande receptvidade e apelo que o tema possuía junto aos mais diversos setores da sociedade brasileira daquele período, destacando o gigantismo de um país, que segundo os discursos, arrancava do atraso e da pobreza para a modernidade, certamente em outros a revista foi também responsável por criar, ainda que parcialmente, aqueles padrões e modelos, evidenciando também através destes exemplos, sua importância para as pesquisas na área de história. 